T. Y. Bogracheva

Y. L. Wang*

T. L. Wang

C. L. Hedley

John Innes Centre (JIC), Norwich Research Park,

Colney, Norwich NR4 7UH, UK

\title{
Structural Studies of Starches with Different Water Contents
}

Received 5 November 2001;

accepted 19 April 2002

\begin{abstract}
The proportion of double helices in starches from a series of pea [rb, rug4-b, rug3-a, and lam-c mutants, and the wild type (WT) parental line], potato and maize (normal and low amylose), and wheat (normal) lines, ranged from about 30-50\% on a dry weight basis. In relatively dry starch powders, only about half of the double helices were in crystalline order, this proportion being higher for A-type than for B-type starches. Using starch from WT pea as an example, it was found that increasing water content results in an increase in total crystallinity. When the water content was raised to a level similar to that in excess water, the proportion of crystallinity was close to the proportion of double helices $(\mathrm{DH})$. Measuring crystallinity in starches with a high water content is difficult using traditional methods such as $x$-ray diffraction. A method was developed, therefore, for determining starch structural characteristics in excess water by measuring the enthalpy of gelatinization transition in quasi-equilibrium differential scanning calorimetry (DSC) experiments. It is suggested that $D H \%=\Delta \mathrm{H}_{s p} \Delta \Delta \mathrm{H}_{D H} \times 100 \%$, where $\Delta \mathrm{H}_{s p}$ and $\Delta \mathrm{H}_{D H}$ represent the specific enthalpies of gelatinisation transition, $\Delta \mathrm{H}_{s p}$ being measured as $\mathrm{J} / \mathrm{g}$ dry starch weight and $\Delta \mathrm{H}_{D H}$ as $\mathrm{J} / \mathrm{g} \mathrm{DH}$, in starch. Studies on potato and maize starches in excess water and in $0.6 \mathrm{M} \mathrm{KCl}$ showed, respectively, that $\Delta \mathrm{H}_{D H}$ was 36.3 and $35.6 \mathrm{~J} / \mathrm{g}$ for B-type polymorphs and 33.0 and $35.0 \mathrm{~J} / \mathrm{g}$ for A-type polymorphs. For $C$-type starches, such as those from pea, intermediate values of $\Delta H_{D H}$, related to the proportions A-/B-polymorphs, should be used. The type of crystallinity in starch can be determined by the shift in peak temperature for thermograms in excess water and in excess $0.6 \mathrm{M}$ $\mathrm{KCl}$. For B-polymorphs this shift was found to be $\sim 2-3^{\circ} \mathrm{C}$ and for A-polymorphs $\sim 7-12^{\circ} \mathrm{C}$. The ratio between ordered areas with both $A$ - and B-polymorphs can be determined from the enthalpies of disruption of each area. These enthalpies can be obtained by deconvolution of bimodal thermograms produced by $C$-type starches in excess $0.6 \mathrm{M} \mathrm{KCl}$. This methodical approach can be applied to all starches that give a sharp gelatinisation thermogram in excess water. Using a range of methods, including DSC, it was found that starch granules from the mutant peas are constructed in a similar way to those from the WT, with B-polymorphs in the centre and A-polymorphs at the periphery of all granules. The proportion of A/B-polymorphs, however, differed between the mutants. It was found that in addition to increasing the total crystallinity, increasing the water
\end{abstract}

Correspondence to: T. Y. Bogracheva; email: tanya.bogracheva@ bbsrc.ac.uk

Contract grant sponsor: EU

Contract grant number: FAIR CT98-3527 (EU)

* Present address: Imperial College, South Kensington, London, SW7 2AZ

Biopolymers, Vol. 64, 268-281 (2002)

(c) 2002 Wiley Periodicals, Inc. 
content within the granules also resulted in an increase in the proportion of B-polymorphs. (C) 2002 Wiley Periodicals, Inc. Biopolymers 64: 268-281, 2002

Keywords: crystallinity; polymorphs; double helices; pea seed mutants; A-, B-, and C-type starches

\section{INTRODUCTION}

Starch is laid down in granules that are almost entirely composed of two glucose polymers, amylose, which is a predominately linear molecule, and amylopectin, which is a much-branched macromolecule. It is generally agreed that starch granules consist of amorphous and ordered areas, and that the ordered areas are formed from the short chains within amylopectin molecules being arranged in clusters. Short- and longrange order structures have been identified within the ordered areas. ${ }^{1-3}$ The short-range order structures have been found to consist of parallel-stranded double helices, and the long-range order arrangements of these double helices give rise to two types of crystalline, or polymorph, structures, A and B. A-type polymorphs are formed from the orthogonal packing of double helices with a small amount of tightly bound structural water..$^{3-8}$ It has been suggested that either four $^{5}$ or eight ${ }^{6}$ water molecules per unit cell are present within A-type polymorphs. B-type polymorphs are formed by a more open hexagonal packing of the double helices, with 36 water molecules per unit cell, some of which are located in channels formed by the hexagonal packing. ${ }^{4,7,9}$ From previous reports ${ }^{10}$ it can be suggested that the water trapped within the A-polymorphs has very low mobility, whereas B-polymorphs have both trapped water with low mobility and "weakly bound" water with higher mobility. It can be suggested that the weakly bound water is the water that fills the channels within the crystallites.

Starches are called A-, B-, or C-type, depending on the type of crystalline structures present in the granules. A-type starches contain A-polymorphs, B-type starches, B-polymorphs, and C-type starches both Aand B-polymorphs, the type of starch being largely dependent on the plant species. The crystallites are arranged in a characteristic way within the granules, such that when viewed in the light microscope under cross polarizers, the observed interference pattern is usually in the form of a so-called "Maltese cross".,11

${ }^{13} \mathrm{C}$ cross-polarization/magic angle spinning $(\mathrm{CP} /$ MAS) NMR methods have been developed for determining short-range order within starches. ${ }^{12-14}$ It has been shown using this technique ${ }^{14}$ that the proportion of double helices (short-range order) is not influenced when the water content is greater than $5 \%$. On the other hand, it is apparent from the literature that crystallinity (long-range order) is dependent on water content. ${ }^{15,16}$ It can be concluded from these observations that short-range order can be determined in starch containing $10-15 \%$ water, while both dry and wet starch should be analysed to determine long-range order.

When starches are heated in excess water, at a particular temperature the granular structure breaks down followed by granular swelling. This process is called gelatinization and is known to be accompanied by endothermic transition, which can be recorded using differential scanning calorimetry (DSC). ${ }^{12,17-20}$ In general, the enthalpy of this transition can be considered to represent an overall process of changes within starch granules. ${ }^{21}$ Irrespective of the crystalline type, starches from non-mutant, or wild type (WT), lines from different species all give a sharp endothermic peak when heated in excess water. Starches obtained from mutants, however, can give different types of gelatinisation transition. Depending on the mutant, this may be a narrow transition, similar to that seen in starch from the WT, or a low broad transition. 2,12,17,22-24 This second type of transition is often attributed to mutants containing mutations affecting branching enzymes associated with amylopectin synthesis-for example, mutations at the $r$ locus in pea (Pisum sativum) and the ae locus in maize (Zea mays). ${ }^{2,19,22,23,25}$ It is also known that this type of gelatinization is characteristic for starches from peas containing a mutation at the rug5 locus, which is known to affect a starch synthase involved in amylopectin synthesis. ${ }^{19,22}$ It can be suggested that the thermodynamic parameters of gelatinization transition are related to the structural characteristics of starch granules equilibrated in excess water. The possibilities of utilizing such a relationship are explored in the present paper.

The first steps in the structural characterization of pea starches have been made and reported earlier. ${ }^{14,17,22-24,26}$ Data presented in these reports have shown that starch from WT peas is composed of complex granules in which B-polymorphs are at the centre and A-polymorphs at the periphery of all the granules. Also, x-ray diffraction was used to demonstrate variation for the proportion of A- and B-polymorphs in relatively dry starches from WT and some pea mutants. ${ }^{22,24}$ These approaches were used to pro- 
duce the data in the present paper together with new approaches that have been developed for determining the structural characteristics of starches equilibrated in excess water.

It has been shown earlier that a sharp endothermic transition during gelatinization results from the swelling of disrupted areas followed by the rapid propagation of disruption along the granule. ${ }^{17}$ The present paper deals only with starches that are characterized by such a transition.

\section{MATERIALS AND METHODS}

\section{Material}

Normal and low amylose (waxy) potato starches were obtained from Avebe Premier (UK) and Avebe (The Netherlands), respectively. Normal and low amylose (waxy) maize starches were obtained from Roquette (France) and Amioca (USA), respectively, and the wheat starch was purchased from Sigma Chemical Co. (USA). Starch from pea seeds was produced from a series of mutants, near-isogenic except for mutations (in parentheses) at either the $r b(r b)$, rug 3 (rug3-a), rug4 (rug4-b), or lam (lam-c) loci, plus the WT parental line from which the mutants were derived. All of the pea starches were extracted and purified as described earlier, ${ }^{22}$ with the exception that after the starch slurry was screened through a $53 \mu$ sieve it was left for $10 \mathrm{~h}$ at $4^{\circ} \mathrm{C}$. The precipitate was collected, resuspended in a large volume of water, and allowed to precipitate again at $4^{\circ} \mathrm{C}$ for $10 \mathrm{~h}$. The resulting starch precipitate was then air dried, during which any lumps were broken down progressively by hand. There were problems sieving the starch from the rug3-a mutant, which were avoided by air classifying the meal before the starch extract was slurried with water. The air classification was carried out using an Alpine Multi-Plex Laboratore Zigzag Classifier 100 MZR (Germany) with an air flow of $46 \mathrm{~m}^{3} / \mathrm{h}$, a motor speed of $7000 \mathrm{rpm}$ and rate of sample feed of $0.7 \mathrm{~kg} / \mathrm{h}$.

\section{Preparation of Starches Prior to Analysis}

Starch powders to be used for NMR and x-ray diffraction (XRD) measurements were equilibrated in a desiccator containing saturated solutions of $\mathrm{K}_{2} \mathrm{CO}_{3}$ at $20-22^{\circ} \mathrm{C}$. Under these conditions, the relative humidity (RH) at $20^{\circ} \mathrm{C}$ was shown to be $44 \%^{27}$ and the final water content of pea, maize, potato, and wheat starches was $13-14,12,15$, and $12 \%$, respectively.

Wet starch powder (from WT pea) for XRD measurements was produced by first equilibrating the starch in excess water. The starch suspension was then centrifuged $(3000 \times g)$ and the supernatant removed. The starch precipitate appeared as a hard wet powder that was slightly more moist at the top. This moisture was dried with tissue paper. The wet starch powder had a water content of $49 \%$. It was apparent that the proportion of water was slightly overestimated, because the precipitated starch granules would have a small amount of free space between them, which would be filled with free water. This overestimation, however, can be considered to be very small as the granules in the precipitate were closely packed. Since the water content within the crystallites is fixed ( $\sim 4 \%$ in A-type and $24 \%$ in B-type $)^{4-7}$ the proportion of water in the amorphous part of starch can be estimated at 55-60\%. It was assumed that total crystallinity and A/B crystallinity were within the range $25-40 \%$ and $40 / 60-50 / 50$ respectively. ${ }^{14,22}$

Amorphous starch samples were produced as described in Bogracheva et al. ${ }^{14}$ and had a water content of 8-9\%. For XRD powder experiments the amorphous starch was placed in a desiccator containing saturated $\mathrm{K}_{2} \mathrm{SO}_{4}(\mathrm{RH} \sim 98 \%)$ for $4 \mathrm{~h}$. After this treatment the water content was $12 \%$, which approximately corresponded to the water content in the amorphous parts of native starches equilibrated at $44 \% \mathrm{RH}$.

For wet starch XRD experiments, the amorphous starch sample was mixed with ice powder and homogenized in liquid nitrogen using a pestle and mortar. This gave a final water content of $58 \%$. Samples subjected to this treatment were prepared just prior to the experiments.

\section{Determination of Water Content}

Water content in native and amorphous starches was determined by calculating the weight loss after the samples were dried to constant weight (for about $48 \mathrm{~h}$ ) in a vacuum oven at $80^{\circ} \mathrm{C}$.

\section{Determination of Amylose/Amylopectin Ratio}

The proportion of amylose/amylopectin was determined using a commercial Megazyme kit (Megazyme International Ireland Ltd). The method is based on the solubilisation of starch using DMSO; the precipitation of amylopectin using concanavalin A; the hydrolysis of the remaining amylose using amyloglucosidase $/ \alpha$-amylase and the spectophotometric determination of the resulting glucose.

\section{NMR Spectroscopy}

${ }^{13} \mathrm{C}$ CP/MAS NMR spectra were determined using a Bruker MSL-300 spectrometer operating at a proton frequency of $300.13 \mathrm{MHz}$ and ${ }^{13} \mathrm{C}$ frequency of $75.46 \mathrm{MHz}$, as described previously. ${ }^{14}$ A total of 1600 scans was accumulated for native starches and 3200 scans for amorphous starches.

An example of an NMR spectrum of starch is shown in Figure 1. Under the experimental conditions used, the amorphous part of the granules was in the glassy state, and NMR spectra could be presented, therefore, as the sum of the amorphous and the ordered parts spectra. ${ }^{14,28}$ In accordance with previous reports, ${ }^{13,14,17,28}$ all the main peaks for $\mathrm{C}_{1}-\mathrm{C}_{6}$ glucose atoms are fitted in the range $110-50 \mathrm{ppm}$. It was found, however, that a rotor speed of $3.5 \mathrm{kHz}$ does 


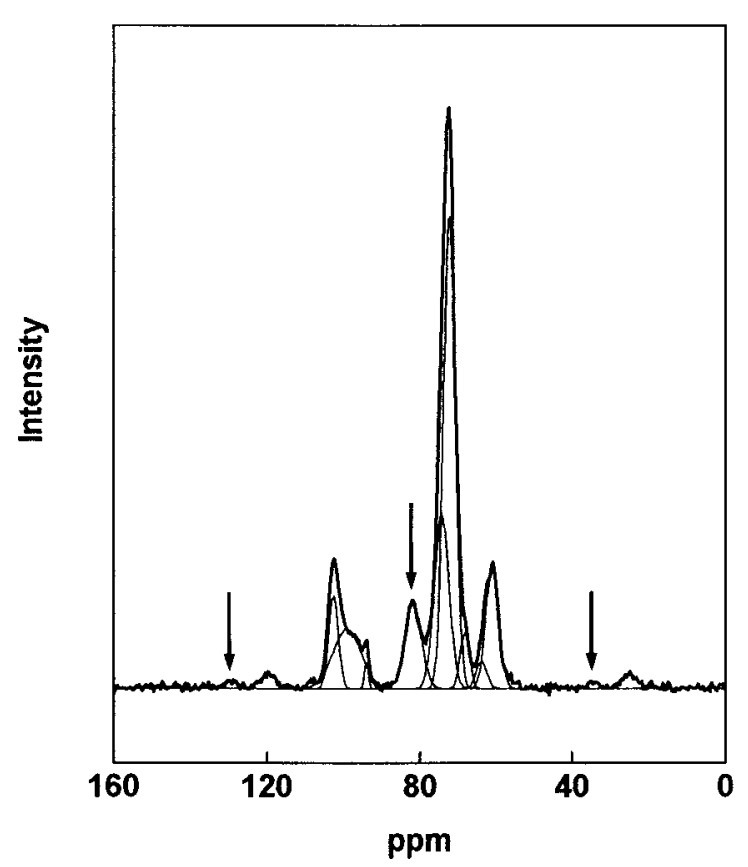

FIGURE 1 Computer fitted peak profile and simulated total pattern superimposed on a ${ }^{13} \mathrm{C} \mathrm{CP/MAS} \mathrm{NMR} \mathrm{pattern}$ for amorphous starch (water content $=8.8 \%$ ) from WT pea. The arrows indicate the peak at $81.5 \mathrm{ppm}$ plus its ssb peaks. Correlation coefficient for fitted curve $=0.998$.

not fully prevent the formation of spinning site bounds (ssb; Figure 1). Although ssb were relatively small they were taken into account in calculations. The peak profiles were determined as described in Bogracheva et al. ${ }^{14}$ The proportion of ordered structures (double helices: DH) was calculated using $\mathrm{C}_{4}$ resonance as a reference for amorphous material, as described previously. ${ }^{14}$ The main $\mathrm{C}_{4}$ resonance was calculated by determining the area of the peak at 81.5 ppm; however, it was corrected by adding, when necessary, the areas of ssb related to this peak.

The proportion of $\mathrm{C}_{4}$ resonance relative to the total area of the spectrum for amorphous starches was found to be 10.1. Therefore, $\mathrm{DH} \%=$ proportion of $\mathrm{C}_{4}$ resonance/10.1 $\times 100 \%$. The total area was calculated in the range $0-160$ ppm.

\section{Wide-Angle X-Ray Diffraction}

The measurements for dry starch powders were made using a Philips Scientific diffractometer operating at $\mathrm{CuK}_{\alpha}$ with a PW 1730/10 generator with an automatic divergence slit (Philips PW 1386/55) was used as described previously. ${ }^{22} \mathrm{~A}$ speed of $0.004^{\circ} 2 \theta / \mathrm{s}$, with a step size of $0.1^{\circ} 2 \theta$ was used The samples were scanned in the range $5.0-40.0^{\circ} 2 \theta$. The total run time was 2 h 26 min.

For crystallinity measurements, the pattern for amorphous starch was fitted to that for the native starch samples, as described in Bogracheva et al. ${ }^{22}$ The total crystallinity was calculated as the proportion of crystalline area to total area at angles between $12.5-27.5^{\circ} 2 \theta$. The proportion of A/B polymorphs in dry starch powders was calculated as described previously, ${ }^{22}$ using peaks at $14^{\circ} 2 \theta$ and $18^{\circ} 2 \theta$, respectively, as references for B- and A-polymorphs.

It was shown that when XRD with the automatic divergence slit was used, the patterns from wet starch powders were distorted particularly at angles between 4 and $12{ }^{\circ} 2 \theta$. For this reason the measurements for wet starch powders were made using an XRD instrument with a fixed slit, where the patterns given by the wet samples were not disturbed. A Philips diffractometer with a PW 1830 generator was used as described previously. ${ }^{22}$ A speed of $0.008^{\circ} 2 \theta / \mathrm{s}$, with a step size of $0.1^{\circ} 2 \theta$ was used. The samples were scanned in the range $4.0-25.0^{\circ} 2 \theta$, a total run time was $44 \mathrm{~min}$, the samples being run immediately after they were moisturized with water.

The higher scanning speed and shorter scanning range were employed because of the necessity to keep scanning time relatively short. There were two main reasons for this. First, during the experiment the top layer of starch dried to some extent. This gave a time limit to the XRD experiment, since drying of the starch surface could result in changes in the pattern produced. It was found, however, that if two consecutive runs were made, each of $44 \mathrm{~min}$, then the data from the second run almost reproduced that from the first. Second, in high water contents there is a possibility of retrogradation of amorphous starch. It was found that when a sample of amorphous starch with high water content was stored for $2.5-3 \mathrm{~h}$ at $20^{\circ} \mathrm{C}$ before an XRD run, small peaks of retrograded material appeared. When, however, the amorphous sample was run immediately after preparation with a run time of about $1 \mathrm{~h}$, a smooth amorphous pattern was produced, showing that no apparent retrogradation had occurred.

With this instrument, however, the irradiated area of the sample was dependent on the angle of $2 \theta$. This dependence was very high at small angles of $2 \theta$, but became very small when the angle was higher than about $10^{\circ} 2 \theta$ (Figure $2 b$ ). The native and fitted patterns for amorphous starches are shown in Figure 2a. The crystallinity for starch samples with a high water content was calculated from pattern areas between 12.5 and $25^{\circ} 2 \theta$. Although the range of $2 \theta$ was slightly shorter than used for the studies with dried powders, it covered all the main peaks, and therefore, allowed an estimate to be made of the total crystallinity. For both instruments, the pattern due to the sample holder was subtracted.

\section{Differential Scanning Calorimetry}

A Setaram Micro-DSC (Lyons, France) was used. The concentration of starch in suspension was $\sim 2.5 \%$. The heating rate was $0.5^{\circ} \mathrm{C} / \mathrm{min}$. The specific enthalpy $\left(\Delta H_{\mathrm{sp}}\right)$, peak temperature $\left(T^{\mathrm{p}}\right)$, overall $\left(t_{\mathrm{o}}, t_{\mathrm{c}}\right)$ and approximated $\left(T_{\mathrm{o}}, T_{\mathrm{c}}\right)$ onset, and conclusion temperatures were determined as shown in Figure 3.

Previous studies have shown that heating 2-4\% starch suspensions in DSC experiments with a heating rate of 


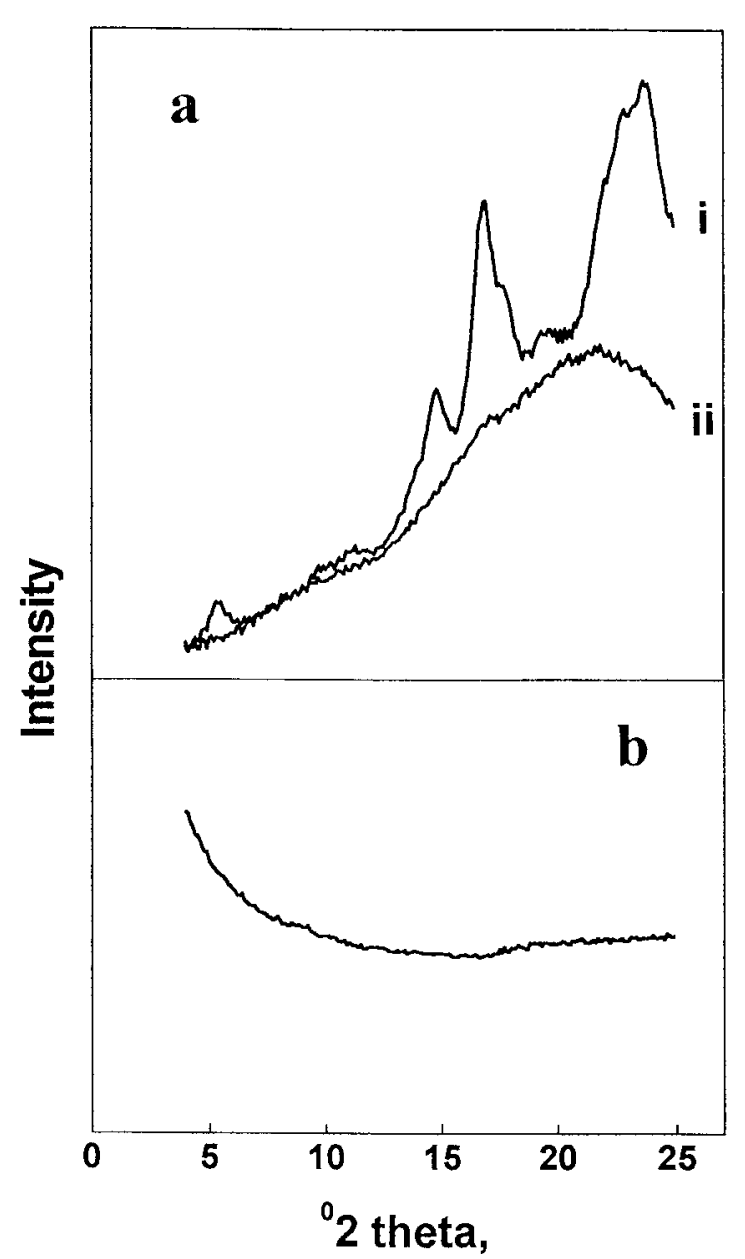

FIGURE 2 (a) XRD pattern for wet ( $\sim 58 \%$ water) amorphous starch (ii) fitted to the pattern for wet ( $\sim 49 \%$ water) native starch from WT pea (i) after subtraction of the XRD pattern for the empty sample holder (2b). The XRD instrument with the $1^{\circ}$ divergence slit was used.

$1{ }^{\circ} \mathrm{C} / \mathrm{min}$ or lower can be considered as near quasi-equilibrium conditions for the gelatinisation process. We have found, however, that the $T^{\mathrm{p}}$ of the endothermic peak when the heating rate was $0.5^{\circ} \mathrm{C} / \mathrm{min}$ was $0.3^{\circ} \mathrm{C}$ lower than when a heating rate of $1^{\circ} \mathrm{C} / \mathrm{min}$ is used. This indicated that a heating rate of $0.5^{\circ} \mathrm{C} / \mathrm{min}$ was closer to quasi-equilibrium then $1{ }^{\circ} \mathrm{C} / \mathrm{min}$. Since the studies reported in the present paper deal with the precise measurement of thermodynamic parameters related to quasi-equilibrium structural changes during gelatinization, the $0.5^{\circ} \mathrm{C} / \mathrm{min}$ heating rate was used.

\section{Polarized Light Microscopy}

Starch samples were prepared using a Mettler FP 82 microscope hot stage. The samples were viewed during heating using a Zeiss Axiophot (West Germany) microscope equipped with cross polarizors, at $400 \times$ magnification. The samples were heated from 30 to $95^{\circ} \mathrm{C}$ at a heating rate of $0.5^{\circ} \mathrm{C} / \mathrm{min}$. The behavior of individual starch granules during heating was viewed.

\section{Computer Modeling}

All manipulations related to background subtraction, curve fitting, peak fitting, and area calculations were performed using Origin software (Microcal, USA). The correlation coefficients were never less then 0.998 .

\section{RESULTS}

\section{Proportion of Short-Order Structures (Double Helices)}

It has been shown previously that providing the moisture level is greater than $5 \%$ the $\mathrm{DH} \%$ in starch granules is independent of the moisture content. ${ }^{14} \mathrm{In}$ the present paper, the $\mathrm{DH} \%$ was measured in starch powders equilibrated at $43.6 \% \mathrm{RH}$ at $20^{\circ} \mathrm{C}$, giving starches with water contents of $12-15 \%$. A comparison between starches from mutant pea, potato, maize, and wheat for $\mathrm{DH} \%$ using ${ }^{13} \mathrm{C}$ CP/MAS NMR is

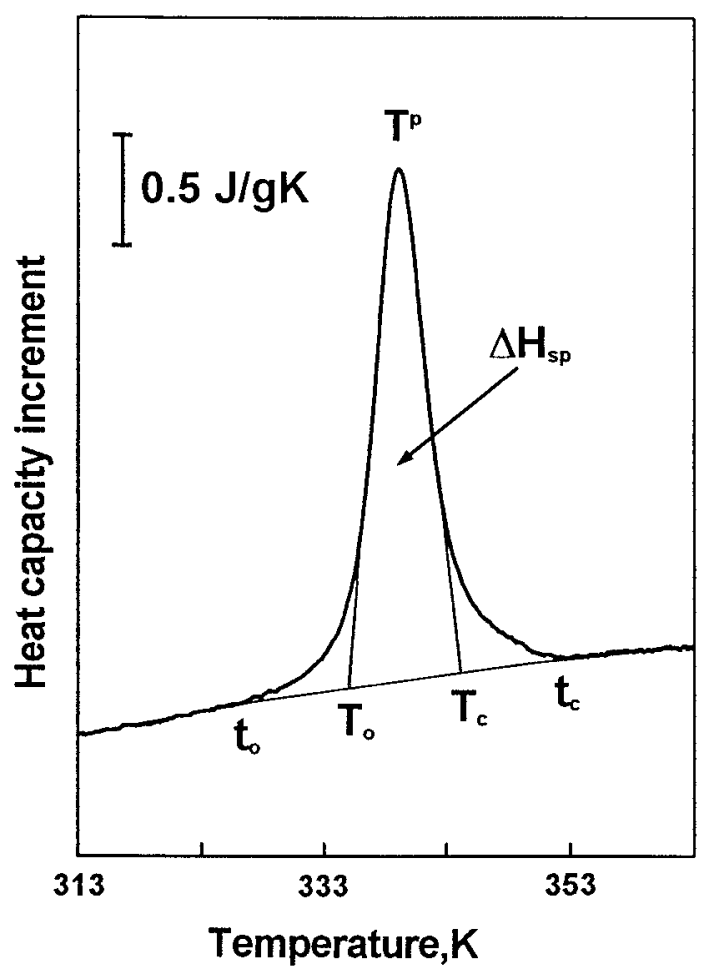

FIGURE 3 DSC thermogram of starch from $r b$ mutant pea. The amount of $17.5 \mathrm{mg}$ starch $+827 \mathrm{ml}$ water heated at $0.5^{\circ} \mathrm{C} / \mathrm{min}$. The specific heat capacity $\left(\Delta H_{\mathrm{sp}}\right)$, peak temperature $\left(T^{\mathrm{p}}\right)$, overall $\left(t_{\mathrm{o}}, t_{\mathrm{c}}\right)$ and approximated $\left(T_{\mathrm{o}}, T_{\mathrm{c}}\right)$ onset and conclusion temperatures were determined as shown. 
Table I Chemical and Structural Characteristics of Starches

\begin{tabular}{|c|c|c|c|c|c|c|c|}
\hline \multirow{2}{*}{$\begin{array}{l}\text { Starch } \\
\text { Source }\end{array}$} & \multirow[b]{2}{*}{ Starch Type } & \multicolumn{5}{|c|}{ Starch Containing $12-15 \%$ Water $^{\mathrm{a}}$} & \multirow{2}{*}{$\begin{array}{c}\text { Starch Containing } \\
\text { c.a. } 49 \% \text { Water } \\
\% \mathrm{~A}: \mathrm{B}^{\mathrm{g}}\end{array}$} \\
\hline & & $\% \mathrm{AP}^{\mathrm{c}}$ & $\% \mathrm{DH}^{\mathrm{d}}$ & $\% \mathrm{Cr}^{\mathrm{e}}$ & $\% \mathrm{DH} / \mathrm{Cr}$ & $\% A: B^{f}$ & \\
\hline WT pea & $\mathrm{C}$ & 71 & 40.6 & 22.6 & 57 & $53: 47$ & $42: 58$ \\
\hline rug4- $b$ pea & $\mathrm{C}$ & 72 & 41.5 & 23.6 & 58 & $53: 47$ & $37: 63$ \\
\hline$r b$ pea & $\mathrm{C}$ & 80 & 48.4 & 27.0 & 56 & $57: 43$ & $49: 51$ \\
\hline rug3-a pea & $\mathrm{C}$ & 89 & 40.8 & 24.0 & 59 & $85: 15$ & $67: 33$ \\
\hline lam-c pea & $\mathrm{C}$ & 90 & 48.4 & 27.2 & 56 & $37: 63$ & $30: 70$ \\
\hline WT potato & $\mathrm{B}$ & 79 & 48.2 & 23.9 & 50 & $0: 100$ & $0: 100$ \\
\hline Waxy potato & $\mathrm{B}$ & 99 & 51.8 & 23.0 & 44 & $0: 100$ & $0: 100$ \\
\hline WT maize & $\mathrm{A}$ & 73 & 37.8 & 23.0 & 61 & $100: 0$ & 100:0 \\
\hline Waxy maize & A & 99 & 47.5 & 31.9 & 68 & 100:0 & $100: 0$ \\
\hline WT wheat & A & 72 & 31.5 & 20.5 & 65 & 100:0 & $100: 0$ \\
\hline
\end{tabular}

${ }^{\text {a }}$ Equilibrated in $44 \%$ RH.

${ }^{\mathrm{b}}$ Equilibrated in excess water.

${ }^{\mathrm{c}}$ Proportion of amylopectin (max error $1 \%$ ).

${ }^{\mathrm{d}}$ Proportion of double helices (max error $0.8 \%$ ).

${ }^{\mathrm{e}}$ Total crystallinity determined using XRD with automatic divergence slit (max error $0.5 \%$ ).

${ }^{\mathrm{f}}$ Proportion of A- to B-polymorphs determined using XRD with automatic divergence slit (max error $2.0 \%$ ).

${ }^{\mathrm{g}}$ Proportion of A:B polymorphs determined using DSC method in excess $0.6 \mathrm{M} \mathrm{KCI}$ (max error $1.0 \%$ ).

shown in Table I. It can be seen from these data that the proportion of ordered structures in starches from the different sources ranged from 30 to $50 \%$. It is believed that the double helices are mainly composed from the short chains of amylopectin. The proportion of amylopectin in the various starches differed significantly (Table I). When the proportion of amylopectin in the starches was compared with the $\mathrm{DH} \%$, it was found that those with a higher proportion of amylopectin (from waxy potato, waxy maize, and lam-c) tended to have a higher DH\%. This was not always the case, however. For example, starch from the rug3-a pea mutant had a similar DH\% to that found in starch from WT pea, even though the amylopectin content in starch from the rug3-a mutant was much higher (Table I). Also, starch from the rug4-b pea mutant and from wheat had a similar proportion of amylopectin, while the $\mathrm{DH} \%$ was higher in the rug4-b mutant $(\sim 42 \%)$ than in wheat $(\sim 31 \%$; Table I). It is clear from the data that not all amylopectin in the starch granules was in an ordered conformation: for example, the $\mathrm{DH} \%$ in waxy maize and waxy potato starches, which are composed almost completely from amylopectin, was only about $50 \%$ (Table I). ${ }^{17}$

\section{Crystallinity}

The type and proportion of crystallinity was studied using XRD. The peak profiles of the crystalline parts from potato, maize, and wheat starches were determined as described in Bogracheva et al. ${ }^{22}$ As ex- pected, the position of the peaks showed that the starches were of B-, A-, and A-type, respectively. It has been shown previously ${ }^{17,22,23}$ that the crystalline parts of starches from WT pea, rug4-b, rb, rug3-a, and lam- $a$ are composed from both A- and B-polymorphs, i.e., they are of C-type. In the current study similar analyses were carried out on starch from the lam-c mutant. The XRD pattern for this starch and the fitted amorphous starch are presented in Figure 4a, and the pattern for the crystalline part of the starch plus the peak profile are shown in Figure $4 b$. The comparison between the peak positions of the polymorphs from the lam-c starch and the peak positions for A- and B-polymorphs (Table II) demonstrated that it is also of C-type.

A summary of the total crystallinity data for starches from the pea mutants and from potato, maize, and wheat is shown in Table I. The water contents of these starches ranged from 12 to $15 \%$ and the proportion of crystallinity from 20 to $32 \%$. It is apparent from these data that in starch powders the proportion of crystallites was much lower than $\mathrm{DH} \%$, which is in agreement with some previously reported data. ${ }^{13}$ It is also apparent from the starches used in the present study that, in general, the A-type starches had a higher DH\% arranged in crystalline (long-range) order then the B-type starches, with the C-type starches being intermediate between the A- and B-type (Table I).

The proportion of A- and B-polymorphs in the starch powders was calculated from XRD data, using the approach described previously. ${ }^{22}$ These propor- 


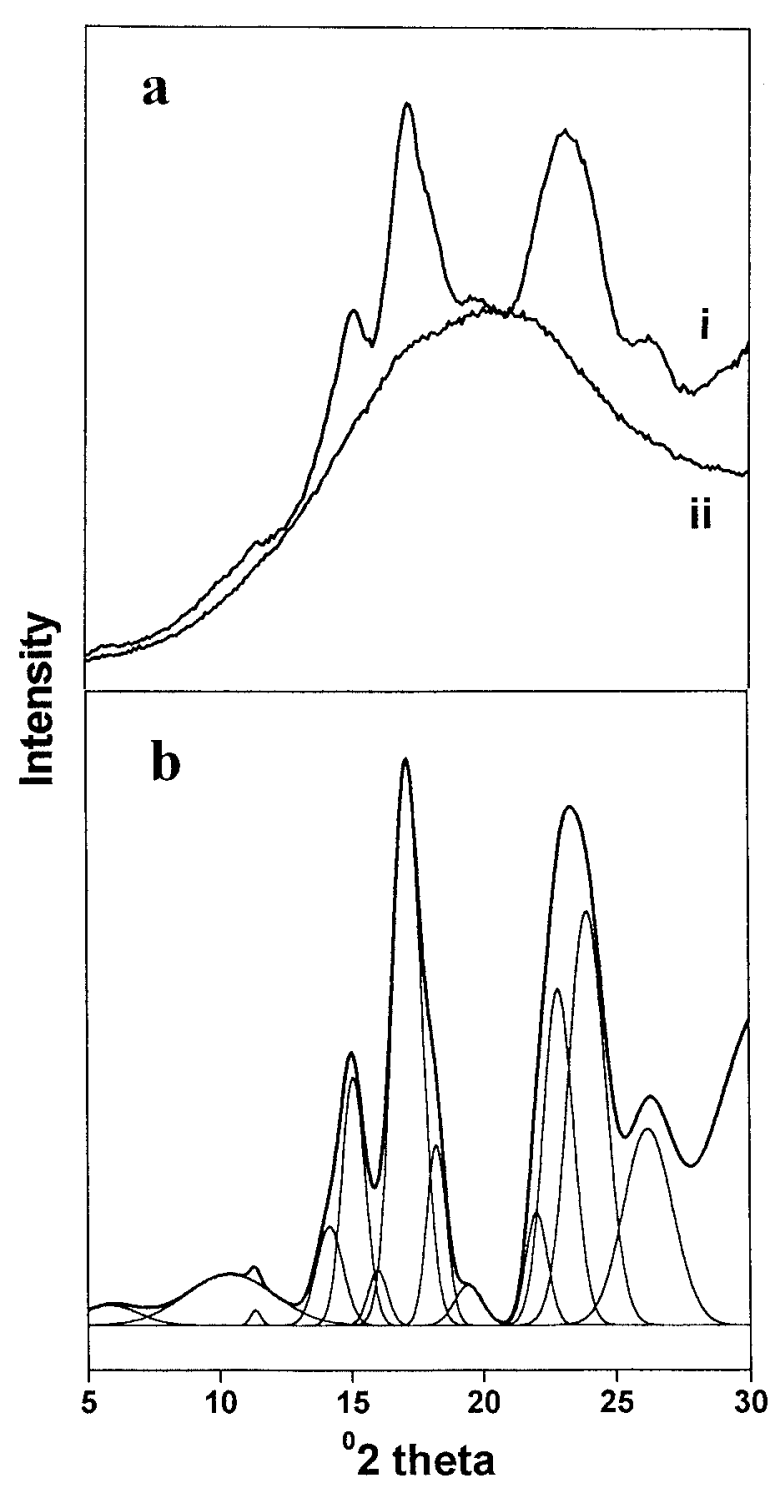

FIGURE 4 (a) XRD patterns for starch (containing 13\% water) from lam-c mutant pea (i) and fitted amorphous starch (containing 12\% water) from WT pea (ii). The XRD instrument with a divergence slit was used and the instrument background was subtracted. (b) Computer-simulated XRD pattern for crystalline portion and peak profile of starch from lam-c mutant pea. Computer peak fitting was performed using Origin software. The correlation coefficient was 0.998 .

tions varied significantly between the starches from the pea mutants. The obtained data, together with results published earlier, showed that the pea mutants ranked rug3- $a>r b>\mathrm{WT}>$ rug4- $b>$ lam- $c$ $>$ lam- $a$, with regard to the proportion of A/B-polymorphs in starch powders with $13-14 \%$ water (Table I). ${ }^{20,22,29}$

An XRD study was carried out using starch powders from WT pea in which the water content was
Table II Peak Positions for Starch Polymorphs Obtained Using Powder X-Ray Diffraction

\begin{tabular}{ccr}
\hline A-Polymorphs $^{\mathrm{a}}$ & B-Polymorphs $^{\mathrm{b}}$ & lam-c \\
\hline- & 5.7 & 5.8 \\
10.0 & 10.1 & 10.4 \\
11.4 & 11.4 & 11.3 \\
- & 14.2 & 14.2 \\
15.1 & 15.2 & 15.1 \\
- & 16.4 & 16.0 \\
17.0 & 17.2 & 17.1 \\
18.1 & - & 18.2 \\
19.6 & 19.7 & 19.4 \\
- & 22.3 & 22.0 \\
23.0 & - & 22.9 \\
24.3 & 24.1 & 23.9 \\
26.3 & 26.2 & 26.2 \\
30.5 & 31.0 & 30.8 \\
33.8 & 34.5 & 34.2 \\
38.3 & 38.5 & 38.3 \\
\hline
\end{tabular}

${ }^{\mathrm{a}}$ Waxy maize starch.

${ }^{\mathrm{b}}$ Potato starch.

increased from 11 to $17 \%$. As a result of this increased water content, there was an increase in the total crystallinity from 20 to $25 \%$ (Table III). Following this result, it was of particular interest to ask how crystallinity would change if starches were moisturized to very high levels. In particular, to determine what the crystallinity would be if starches were equilibrated in excess water. The results indicated that the crystallinity of the wet starch powders was increased further compared with the starches containing 17\% water (Table III), the crystallinity content coming very close to the $\mathrm{DH} \%$ in this starch.

It can be suggested that increases in total crystallinity with increasing water content in starch powders

Table III Influence of Water Content on Structural Characteristics of Starch from WT Pea ${ }^{a}$

\begin{tabular}{ccc}
\hline$\%$ Water Content & $\% \mathrm{Cr}^{\mathrm{b}}$ & $\% \mathrm{~A}: \mathrm{B}^{\mathrm{c}}$ \\
\hline 11 & 20.0 & $57: 43$ \\
13 & 22.6 & $53: 47$ \\
17 & 25.1 & $47: 53$ \\
49 & 33.4 & $42: 58$ \\
\hline
\end{tabular}

${ }^{a}$ The data for starch with 11,13 , and $17 \%$ water were produced using XRD with the automatic divergence slit. For $49 \%$ water $\mathrm{Cr}$ data was determined using the XRD with $1^{\circ}$ fixed divergence slit and the A:B data using DSC.

b Total crystallinity (max error was $0.5 \%$ for starch with 11,13 , and $17 \%$ water, and $1.0 \%$ for starch with $49 \%$ water).

${ }^{\mathrm{c}}$ Proportion of A- to B-polymorphs (errors were 2, 1, 1, and 1 for starch with $11,13,17$, and $49 \%$ water, respectively). 
could result in changes in the proportion of A- and B-polymorphs. Indeed, it was shown that the proportion of B-polymorphs was increased from 43 to $53 \%$ when the water content was increased from 11 to $17 \%$ (Table III). The calculation of the A- to B-polymorph ratio from the patterns produced for starches with about $50 \%$ water was not possible, however, as the experiment was performed with the fixed slit XRD apparatus. $^{22}$

It is apparent that the content of A- and B-polymorphs and of total crystallinity in starch powders are relative values, dependent to a large extent on the water content of the starch. It is also clear that for characterizing the granular structure of C-type starches, such as from pea, the proportions of A- and B-crystallites should be measured when starches are equilibrated in excess water conditions. We have now shown that it is not possible to make these measurements using XRD.

\section{The Use of DSC to Determine the Crystalline Structure of Starches in Excess Water}

It was shown that no peak was recorded if the sample was cooled down immediately after transition and then heated up again, indicating that gelatinization transition was not reversible. The enthalpy of gelatinization includes the disruption of double helices and crystallites, the partial solubilization of amylose, and the development of chain-water and chain-chain interactions. From a general point of view, it can be considered that changes happening within the amorphous parts give a minor input into the enthalpy of transition. ${ }^{21}$ This enthalpy can be presented, therefore, per dry weight of ordered structures $\left(\Delta H_{\mathrm{DH}}\right)$.

Quasi-equilibrium gelatinization thermograms for A- and B-type starches in excess water, represented as relatively narrow endothermic peaks, are shown in Figure 5a. In accordance with previously published data, starches from low amylose or waxy mutants have higher $T^{\mathrm{p}}$ then starches from the WT of the same species. ${ }^{12,30}$ In addition, A-type starches (e.g., maize), in general, have been found to have higher $T^{\mathrm{p}}$ than B-type (e.g., potato). The exception is wheat starch, which is the only known A-type starch with a $T^{\mathrm{p}}$ in excess water that is similar to potato starch. ${ }^{12,17,24,31-33}$ A second peak ( $a-l$ in Figure $5 \mathrm{a}$ ) with a higher $T^{\mathrm{p}}$ was found for maize and wheat starches, which on cooling and reheating was completely reversible. This indicated that the nature of the $a-l$ peaks was the disruption and reformation of amylose-lipid complexes. $^{34-36}$
The thermograms for A- and B-type starches in excess $0.6 \mathrm{M} \mathrm{KCl}$, shown in Figure 5b, are represented also by relatively narrow endothermic peaks. Under these conditions, the $a-l$ peaks were again found for maize and wheat starches. For starches from different species $\Delta T$ was found to cover a range of $6-13^{\circ} \mathrm{C}$. For starches from the same species, however, no difference in $\Delta T$ was found in excess water or salt solution (Table IV). In agreement with previous reports, ${ }^{17,24,37}$ a shift in $T^{\mathrm{p}}$ was found for endotherms in salt solution compared with excess water (Figures $5 \mathrm{a}$ and b). This shift was found to be much larger for A-type $\left(7-9^{\circ} \mathrm{C}\right)$ than for B-type $\left(2^{\circ} \mathrm{C}\right)$ starches (Table IV). ${ }^{16,24}$

Measurement of the gelatinization enthalpies for A- and B-type starches was determined only for potato, waxy potato, and waxy maize (Table V). In the case of maize and wheat starches, the $a-l$ peaks slightly overlapped the gelatinization peaks, which made the precise measurement of $\Delta H_{\mathrm{sp}}$ for these starches very difficult. The similarity between WT and waxy potato for $\Delta H_{\mathrm{DH}}$ indicated that the input of amylose solubility into this parameter was very little. A small difference was found in $\Delta H_{\mathrm{DH}}$ between starches with A- and B-polymorphs, $\Delta H_{\mathrm{DH}}$ for potato starches being slightly bigger than for maize starch. It can be suggested that this small difference, which was much smaller in excess salt solution than in excess water, is related to differences in the disruption of Aand B-polymorphs.

The thermograms for starches from the mutant peas in excess water are represented as relatively narrow endothermic peaks (Figure $5 \mathrm{c}$ ). The $T^{\mathrm{p}}$ for starch from the rug4- $b$ mutant was similar to that from the WT. $T^{\mathrm{p}}$ was, however, increased relative to the WT for starches from the other three mutants. The $\Delta T$ values for the mutants ranged from 7 to $12^{\circ} \mathrm{C}$ (Table IV).

The quasi-equilibrium endotherms for starches from the pea mutants in excess $0.6 \mathrm{M} \mathrm{KCl}$ are shown in Figure $5 \mathrm{~d}$. The $\Delta T$ for the transitions ranged from 17 to $26^{\circ} \mathrm{C}$, i.e., more than two times higher then for the transitions of the same starches in excess water (Table IV). The $\Delta H_{\mathrm{sp}}$ and $\Delta H_{\mathrm{DH}}$ for the different pea starches are shown in Table V. Although significant differences were found in $\Delta H_{\mathrm{st}}$ between the starches, the $\Delta H_{\mathrm{DH}}$ values were found to be very similar. Taking into account the errors of determination, it can be seen that the values of $\Delta H_{\mathrm{DH}}$ ranged between those found for A- and B-type starches (Table V). It was reported previously that gelatinization endotherms for starches from the WT and $r b$ mutant are represented as bimodal curves. ${ }^{17,23,24}$ Starches from the other three pea mutants (rug3-a, rug4-b, and lam-c) also have double peak endotherms in the salt solution conditions (Figure 5d). It has been shown also that for starch from WT pea the shift for the first peak was similar to 


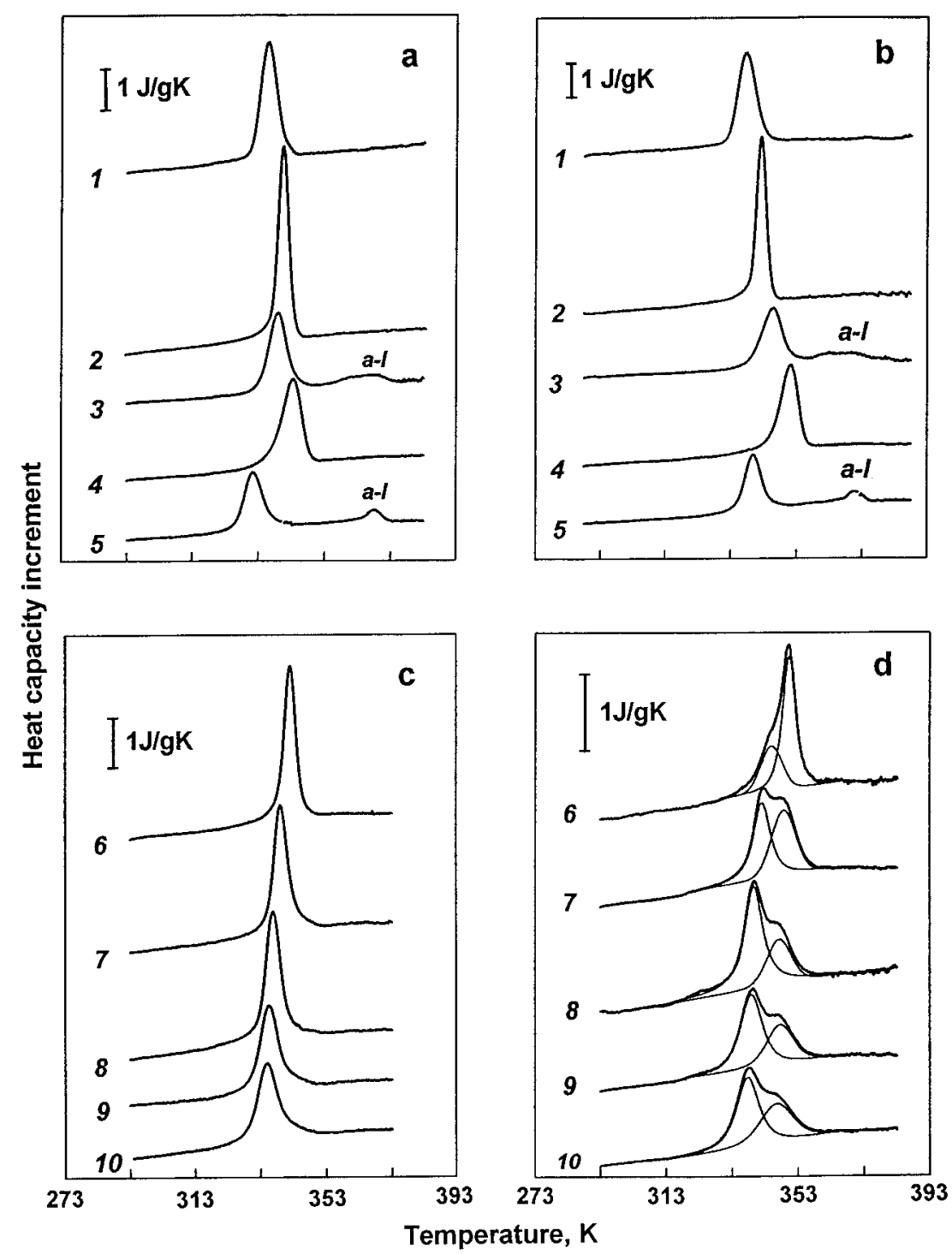

FIGURE 5 (a-d) DSC thermograms of A- and B-type (a and b) and C-type (c and d) starches. Analyses were carried out using about $25 \mathrm{mg}$ starch plus about $820 \mathrm{mg}$ of either water (a and c); or $0.6 \mathrm{M} \mathrm{KCI}\left(\mathrm{b}\right.$ and $\mathrm{d}$ ), with a heating rate of $0.5^{\circ} \mathrm{C} / \mathrm{min}$. In addition peak profiles produced by deconvolution bimodal thermograms for starches from WT and mutant peas in excess $0.6 M \mathrm{KCI}$ are shown (d). Starch sources: 1, WT potato; 2 , waxy potato; 3 , WT maize; 4 , waxy maize; 5 , wheat; 6, rug3- $a$ pea; 7, rb pea; 8 , lam-c pea; 9, rug4- $b$ pea, and 10, WT pea. a-1 indicates the disruption of amylose-lipid complexes.

the peak shift observed for B-type potato starch and was related to the disruption of B-polymorphs. ${ }^{17,23}$ The shift for the second peak was more similar to the peak shift observed for A-type maize starch and was related to the disruption of A-polymorphs. ${ }^{17,23}$

A deconvolution procedure was applied to the bimodel patterns of the starches from WT and mutant peas in excess $0.6 M \mathrm{KCl}$ (Figure $5 \mathrm{~d}$ ). $T^{\mathrm{p}}$ was calculated for each of the resulting two peaks. The shifts in $T^{\mathrm{p}}$ for each of these peaks from the $T^{\mathrm{p}}$ in excess water are shown in Table IV. The first peak had a relatively small shift in peak temperature $\left(2-3^{\circ} \mathrm{C}\right)$, which was similar to the shift for B-type starches (Table IV). The second peak was shifted significantly $\left(8-12^{\circ} \mathrm{C}\right) \mathrm{com}-$ pared with the starch peaks in excess water. The shift for the second peak was found to be similar to the peak temperature shift for A-type starches (Table IV). It can be suggested, therefore, that the first peak represents the disruption of ordered structure in the areas where B-polymorphs are arranged and the sec- 
Table IV Temperature Characteristics of Starches Gelatinized in Excess Water and $\mathbf{0 . 6 M} \mathrm{KCl}^{\mathrm{a}}$

\begin{tabular}{|c|c|c|c|c|c|c|}
\hline $\begin{array}{l}\text { Starch } \\
\text { Source }\end{array}$ & $\begin{array}{c}\text { Starch } \\
\text { Type }\end{array}$ & $\begin{array}{c}T_{\text {water }}^{\mathrm{p}} \\
(\mathrm{K})\end{array}$ & $\begin{array}{c}\Delta T_{\text {water }} \\
(\mathrm{K})^{\mathrm{b}}\end{array}$ & $\begin{array}{l}\Delta T_{\mathrm{s}} \\
(\mathrm{K})\end{array}$ & $\begin{array}{c}T_{\mathrm{s}}^{\mathrm{p} 1}- \\
T_{\text {water }}^{\mathrm{p}}(\mathrm{K})^{\mathrm{c}}\end{array}$ & $\begin{array}{c}T_{\mathrm{s}}^{\mathrm{p} 2}- \\
T_{\text {water }}^{\mathrm{p}}(\mathrm{K}) \\
\end{array}$ \\
\hline WT potato & B & 63.0 & 10 & 11 & 1.7 & NP \\
\hline Waxy potato & $\mathrm{B}$ & 67.3 & 6 & 6 & 1.8 & $\mathrm{NP}$ \\
\hline WT maize & A & 66.0 & 12 & 13 & NP & 7.0 \\
\hline Waxy maize & $\mathrm{A}$ & 70.6 & 11 & 10 & NP & 7.7 \\
\hline Wheat & $\mathrm{A}$ & 58.4 & 12 & 10 & NP & 8.6 \\
\hline WT pea & $\mathrm{C}$ & 62.0 & 12 & 26 & 2.7 & 11.5 \\
\hline rug4- $b$ pea & $\mathrm{C}$ & 62.9 & 11 & 25 & 3.0 & 11.6 \\
\hline$r b$ pea & $\mathrm{C}$ & 66.1 & 9 & 20 & 2.9 & 9.5 \\
\hline rug3-a pea & $\mathrm{C}$ & 69.1 & 7 & 17 & 1.9 & 7.9 \\
\hline lam-c pea & $\mathrm{C}$ & 63.8 & 9 & 22 & 2.6 & 10.3 \\
\hline
\end{tabular}

${ }^{a}$ Heating rate $-0.5^{\circ} \mathrm{C} / \mathrm{min}$; s- $0.6 \mathrm{MCI}$.

${ }^{\mathrm{b}} \Delta T=T_{\mathrm{c}}-T_{\mathrm{o}} \dot{ }$

${ }^{\mathrm{c}} T^{\mathrm{p} 1}$ and $T^{\mathrm{p} 2}$ are peak temperatures for first and second peaks.

${ }^{\mathrm{d}} \mathrm{NP}-$ no peaks.

ond the disruption of the structures in the A-polymorph areas.

The values for $\Delta H_{\mathrm{DH}}$ of the two peaks were used to calculate the proportion of the granule area with Aand B-polymorphs. The small difference in the $\Delta H_{\mathrm{DH}}$ for A- and B-polymorphs in excess $0.6 \mathrm{M} \mathrm{KCl}$ was taken into account in these calculations. A comparison between the proportions of A- and B-polymorphs in wet and dry conditions showed that the amount of $\mathrm{B}$-polymorphs is increased when the water content in the granules is increased (Table III).

\section{Arrangement of A- and B-Polymorphs in Starches from Mutant Peas}

The disruption of crystallinity during heating in excess water resulting in endothermic transition, ${ }^{12,17}$ can be viewed in a light microscope using crossed polarizers. ${ }^{17}$ By viewing under polarized light, the progressive disruption of crystallinity in individual starch granules from WT peas during heating in excess $0.6 \mathrm{M}$ $\mathrm{KCl}$, it was possible to determine which areas within the granules contained A- and B-crystallites. ${ }^{17}$ It was found that the B-crystallites were arranged in the center and the A-crystallites at the periphery of all the granules.

The same approach was used to study the A- and B-crystalline arrangements in starch granules from the four mutant peas. The progressive disruption of granules from lam-c starch during heating in salt solution is shown in Figure 6. It was found that although individual granules are not identical in that they become disrupted at slightly different temperatures, the disruption of all the granules happened in a similar

Table V Gelatinization Transition Enthalpies of Starches in Excess Water and 0.6M KCl

\begin{tabular}{|c|c|c|c|c|c|}
\hline \multirow[b]{2}{*}{$\begin{array}{l}\text { Starch } \\
\text { Source }\end{array}$} & \multirow[b]{2}{*}{$\begin{array}{c}\text { Starch } \\
\text { Type }\end{array}$} & \multicolumn{2}{|c|}{ Water } & \multicolumn{2}{|c|}{$0.6 M \mathrm{KCl}$} \\
\hline & & $\begin{array}{r}\Delta H_{\mathrm{st}}{ }^{\mathrm{a}} \\
(\mathrm{J} / \mathrm{g})\end{array}$ & $\begin{array}{c}\Delta H_{\mathrm{DH}}{ }^{\mathrm{b}} \\
(\mathrm{J} / \mathrm{g})\end{array}$ & $\begin{array}{l}\Delta H_{\mathrm{st}} \\
(\mathrm{J} / \mathrm{g})\end{array}$ & $\begin{array}{r}\Delta H_{\mathrm{DH}} \\
(\mathrm{J} / \mathrm{g})\end{array}$ \\
\hline WT potato & B & 17.2 & 35.7 & 17.2 & 35.7 \\
\hline Waxy potato & $\mathrm{B}$ & 19.2 & 37.0 & 18.4 & 35.5 \\
\hline Waxy maize & A & 15.7 & 33.0 & 16.6 & 35.0 \\
\hline WT pea & $\mathrm{C}$ & 13.7 & 33.7 & 14.1 & 34.7 \\
\hline$r u g 4-b$ pea & $\mathrm{C}$ & 13.4 & 32.3 & 13.6 & 32.8 \\
\hline lam-c pea & $\mathrm{C}$ & 16.6 & 34.2 & 16.9 & 34.9 \\
\hline$r b$ pea & $\mathrm{C}$ & 15.5 & 32.0 & 16.2 & 33.5 \\
\hline rug3- $b$ pea & $\mathrm{C}$ & 14.4 & 35.3 & 14.6 & 35.8 \\
\hline
\end{tabular}

${ }^{\text {a }} \Delta H_{\text {st }}$-specific enthalpy/g dry weight starch (relative error $=\sim 1 \%$ ).

${ }^{\mathrm{b}} \Delta H_{\mathrm{DH}}$-specific enthalpy/g double helices (relative error $=\sim 2.4 \%$ ). 


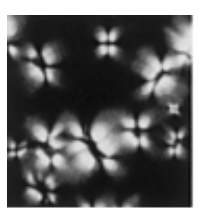

40

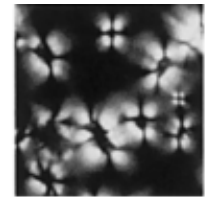

63

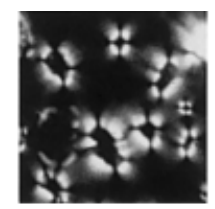

65

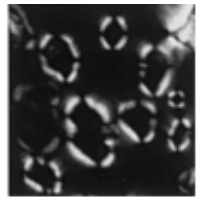

68

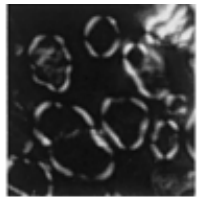

71

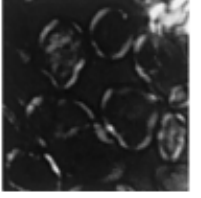

73

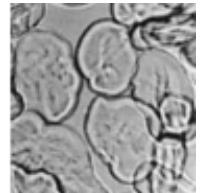

76

FIGURE 6 Polarized-light micrographs $(400 \times$ magnification) of starch granules from lam-c pea during their gelatinization in $0.6 \mathrm{M} \mathrm{KCl}$. A microscope hot stage was used with a heating rate of $0.5^{\circ} \mathrm{C} / \mathrm{min}$. Observation temperatures are indicated in the figure. The photograph at $76^{\circ} \mathrm{C}$ was taken without the polarizer.

way and within the temperature interval, $t_{\mathrm{o}}-t_{\mathrm{c}}$. Similar observations were made for granules from the other three mutant peas. In order to see this process more clearly, the changes occurring in individual granules from the starch of each of the four mutants during heating is shown in Figure $7 \mathrm{a}-\mathrm{d}$. It is clear that in each case the disruption begins in the middle of the granule and then propagates around the granule accompanied by progressive swelling, the process being similar to that observed for starch from WT pea. ${ }^{17}$ The disruption temperature, however, was different for starch from each mutant and was related to the gelatinization temperature measured by DSC.

On the basis of the observations made under polarized light, in conjunction with the DSC results, it can be concluded that all the starch granules from the four near-isogenic mutant pea lines are constructed in a similar way to starch granules from the WT parental line. In each case the B-polymorphs are arranged centrally and the A-polymorphs peripherally, resulting in all of these starches giving a double peak of gelatinization transition in salt solution.

\section{DISCUSSION}

In the dry starch powders only about half of the double helices were found to be arranged within crystalline order. It is known that the crystalline structures need a certain proportion of structural water. ${ }^{4-8}$ On the other hand, the amorphous parts also have a tendency to bind a proportion of water. In conditions

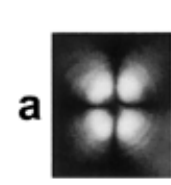

$40 \mathrm{C}$

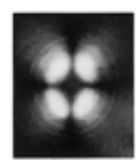

$65 \mathrm{C}$

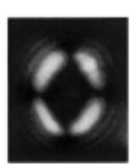

$68 \mathrm{C}$

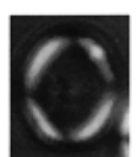

$71 \mathrm{C}$

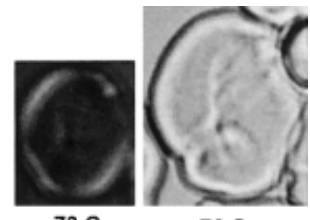

$73 \mathrm{C} \quad 76 \mathrm{C}$

b
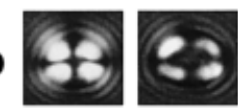

$63 \mathrm{C}$
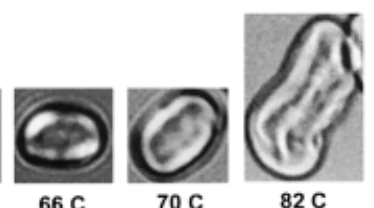

$70 \mathrm{C}$

$82 \mathrm{C}$

C
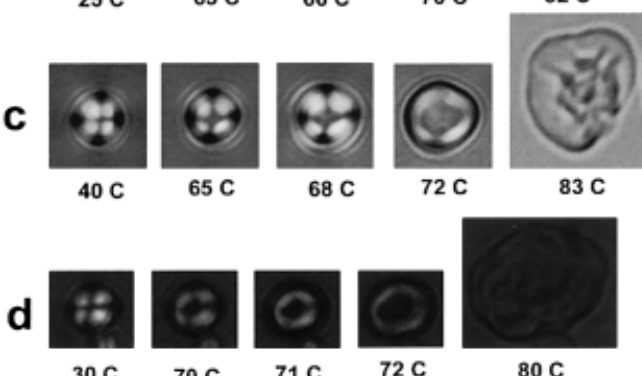

$72 \mathrm{C}$

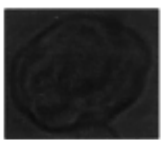

$80 \mathrm{C}$

FIGURE 7 (a-d) Polarized-light micrographs (400× magnification) of individual starch granules from different pea mutants during their gelatinization in $0.6 \mathrm{M} \mathrm{KCl}$. A microscope hot stage was used with a heating rate $0.5^{\circ} \mathrm{C} / \mathrm{min}$. (a) lam-c, (b) $r u g-b$, (c) $r b$, and (d) $r u g 3-a$. Observation temperatures are indicated in the Figure. (a) $76^{\circ} \mathrm{C}$, (b) $82^{\circ} \mathrm{C}$, and (c) $83^{\circ} \mathrm{C}$ were taken without the polarizer. 
where water is limiting, therefore, it will distribute between these two parts of the granule, and as a result, a proportion of the double helices would not have enough water for crystalline order arrangement. It can be suggested that when starches are dried-for example, as part of a starch extraction procedure-their crystallites lose water from the edges, resulting in double helices losing their long-range order at the edges of crystallites. This could result in crystallites getting smaller in size, while at the same time the total crystallinity would be reduced. A-type starches require less crystalline water than B-type ${ }^{4-8}$ which would explain why A-type dry starch powders have a higher proportion of double helices within their crystalline order then B-type. The greater the water content in starch powders the greater the chance for more double helices to align in long-range order. As a result, in excess water almost all double helices should be arranged within crystallites, which is in agreement with the results presented in this paper.

One of the common properties of all the starches studied in the present paper was that they produced a relatively narrow endothermic peak when heated in excess water in DSC experiments. The area of this peak represents the enthalpy of the gelatinization transition. The value of $\Delta H_{\mathrm{DH}}$ was found to be very similar for all the starches, irrespective of the crystalline type or the proportion of amylose (Table V), which corresponds to some previously reported data. ${ }^{12}$ In general, it was found for all the starches that the average value for $\Delta H_{\mathrm{DH}}$ in excess water was 34 $\pm 2 \mathrm{~J} / \mathrm{g}$ and was slightly higher in excess $0.6 \mathrm{M} \mathrm{KCl}$ $(35 \pm 2 \mathrm{~J} / \mathrm{g})$. The small differences in $\Delta H_{\mathrm{DH}}$ found between different starches could be related, however, to differences in swelling properties, to the proportion of A- and B-polymorphs, and perhaps to some extent, to amylose solubilization. The calculations made on the basis of A- and B-type starches (Table V) gave values for $\Delta H_{\mathrm{DH}}$ of 33.0 and $36.3 \mathrm{~J} / \mathrm{g}$ in excess water, and 35.0 and $35.6 \mathrm{~J} / \mathrm{g}$ in excess $0.6 \mathrm{M} \mathrm{KCl}$, respectively. It can be seen that $\Delta H_{\mathrm{DH}}$ for B-type was slightly higher than for A-type, although in salt solution this difference was almost negligible. This difference in $\Delta H_{\mathrm{DH}}$ can be accounted for by the difference in the enthalpies related to the disruption of Aand B-polymorphs. An approximate calculation of the proportion of ordered structures in A- and B-type starches can be derived from measurements of the enthalpy of gelatinization transition in quasi-equilibrium DSC experiments in excess water or $0.6 \mathrm{M} \mathrm{KCl}$. For starches with an unknown crystalline structure, the average values of $\Delta H_{\mathrm{DH}}$ in excess water $(34.7 \mathrm{~J} / \mathrm{g})$ and excess $0.6 \mathrm{M} \mathrm{KCl}(35.3 \mathrm{~J} / \mathrm{g})$ could be used for this type of measurement. Excess salt solution, however, would be preferable, since in practice $\Delta H_{\mathrm{DH}}$ is effectively not dependent on the type of crystallinity in these conditions.

In excess water, the ordered parts of the granules are represented by double helices that are mainly arranged within long-range (crystalline) order. The enthalpy of gelatinization can be considered to represent the overall process of changes within the granules, ${ }^{21}$ which mainly includes the disruption of longand short-range order and granular swelling. The disruption of short-range order probably contributes the largest input into $\Delta H_{\mathrm{sp}}$; however, the input of other processes cannot be excluded. It was found that the disruption of A- and B-type long-range order gave very similar inputs into $\Delta H_{\mathrm{sp}}$, and therefore, the contribution of long-range order disruption into $\Delta H_{\mathrm{sp}}$ can be represented as per proportion of double helices. It is known that swelling can differ to a great extent between starches. ${ }^{38}$ The first water layer around the polymer chain, however, is known to give the main energetic input during swelling. The contribution of swelling into $\Delta H_{\mathrm{sp}}$, therefore, also should be mainly dependent on the proportion of double helices and not on the type of starch. On this basis, it was suggested that $\Delta H_{\mathrm{sp}}$ can be used to calculate the proportion of double helices in starch.

It has been shown previously that all granules of WT pea starch have a complex structure-B-polymorphs on the inside and A-polymorphs on the outside-and this granular architecture is reflected in the gelatinisation behaviour of individual granules. ${ }^{17}$ When this starch is heated in excess salt solution, at a particular temperature the crystalline structure of the granule first begins to disrupt in the hilum area, followed by swelling in the disrupted area. Since the hilum in pea starch is arranged in the middle of the granule the increase in granule volume is restricted by the flexibility of nondisrupted areas at the periphery. A model has been suggested in which the higher proportion of water in disrupted areas of the granule results in a decrease in the melting temperature of neighboring areas. ${ }^{17}$ This results in a rapid propagation of the disruption process across the central part of the granule, where B-polymorphs are arranged. The peripheral areas of the granules, containing the Apolymorphs, begin to melt several degrees higher, after the central areas containing the B-polymorphs have concluded melting and is followed by high granular swelling. Such a melting process is reflected in the bimodal endothermic transition, the melting of the B-polymorphs giving the first peak followed by the melting of the A-polymorphs, giving the second peak. As suggested previously, ${ }^{17}$ this type of gelatinization (or melting of individual granules in excess water) can 
be explained on the basis of the Flory theory of "melting point depression." 39 Salt solution absorbed by the amorphous part of the granule plays a role of plastisizer in the process. Double helices in A-polymorphs are more tightly packed than in B-polymorphs (i.e., they have a smaller volume per polymer unit) and therefore should have a higher melting temperature.

The difference between A- and B-polymorphs, however, is not only in the symmetry and density of their packing, but also in the mobility of their structural water. ${ }^{10}$ In addition to "trapped water" (tightly bound within the crystallites) components, which are common to both types of starches, B-polymorphs also have anisotropic "weakly bound" water, which is probably located in channels within the crystallites. ${ }^{9}$ This weakly bound water has a higher mobility than trapped water, ${ }^{10}$ and it can be suggested that it becomes more mobile during heating and also destabilizes crystallites. This weakly bound water would, therefore, play the role of additional plasticizer for B-crystallites, although its effectiveness obviously would be much smaller then the "bulk" plasticizer (within the amorphous part). It can be suggested that this will reduce the effect of increasing the melting temperature in salt solution, which would result in B-polymorphs having a $T^{\mathrm{p}}$ that was more similar to that found in water, compared with the differences between salt solutions and water found for A-polymorphs. Since starch granules are not absolutely identical, the DSC thermogram represents the sum of all granules melting in the starch sample. For this reason the two peaks are seen to overlap, but as was shown in the present paper, they can be separated by deconvolution. The area of each peak then represents the melting enthalpy of each type of polymorph.

It is obvious that the difference in melting temperature for A- and B-polymorphs should depend on the type of plasticizer. Structure-making salts are known to increase chain-chain interactions, ${ }^{40}$ and it can be suggested, therefore, that their presence will result in an increase in the melting temperature for crystallites. As reported previously, the double peak patterns can be obtained for C-type pea starches in excess solutions of different structure making salts (KCI, $\mathrm{NaCl}$, $\mathrm{Na}_{2} \mathrm{SO}_{4}$, and $\left.\mathrm{Na}_{2} \mathrm{PO}_{4}\right),{ }^{24,37}$ the peak positions being dependent on the concentration of the salt solution. In these earlier reports it was shown that increasing the salt concentration to about $1 M$ resulted in a progressive increase in the differences in $T^{\mathrm{p}}$ between the two peaks. The amount of $0.6 \mathrm{M} \mathrm{KCl}$ was found to give a good peak separation and was used, therefore, in the experiments presented in the current paper. It is apparent that this separation happens also in excess water, but the difference in melting temperature for A- and B-polymorphs in water is relatively small and the two peaks were not usually resolved. ${ }^{23}$

As was shown, the recognizable difference in $T^{\mathrm{p}}$ shift between A- and B-type starches in excess water/ salt solution can be used to determine the type of crystallinity in starch. Quasi-equilibrium DSC experiments in excess water and salt solutions can be used, therefore, for structural studies of starches with a high water content, including determining the proportion of ordered structures, the type of crystallinity, and the ratio between ordered areas containing A- and Bpolymorphs. Such measurements are faced with significant problems when other more direct methods (e.g., XRD) are used. The proposed DSC-based methods give good opportunities for structural studies of starches equilibrated in excess water, with the proviso that they can be applied only to those starches showing a sharp endothermic transition during gelatinisation.

We would like to thank Paul Cairns (IFR, Norwich) for providing the XRD pattern for one dry WT pea starch sample. We would also like to thank Megazyme International Ireland Ltd, and Cheryl Meares (JIC) for carrying out the amylose/amylopectin analysis of the starches, and Dr. Rebrov (IPS, NMR Centre RAS, Moscow) for helpful discussions on the NMR analyses. We acknowledge financial support from the EU (FAIR CT98-3527) and from the BBSRC, as part of a LINK grant (FILMSTARCH), and for core funding to the JIC.

\section{REFERENCES}

1. Hizukiri, S.; Takagi, T. Carbohydr Res 1984, 134, $1-10$.

2. Banks, W.; Greenwood, C. T. Starch and Its Components; Edinburgh University: Edinburgh, 1975.

3. Whistler, R. L.; BeMiller, J. N.; Paschall, E. F. Starch: Chemistry and Technology; Academic Press: San Diego, CA, 1984; Chap 7.

4. Imberty, A.; Perez, S. Biopolymers. 1988, 27, 12051221.

5. Imberty, A.; Chanzy, H.; Perez, S. J Mol Biol 1988, 201, 365-378.

6. Sarko, A.; Wu, H-C. H. Starch/Stärke 1978, 30, 73-78.

7. Wu, H-C. H.; Sarko, A. Carbohydr Res 1978, 61, 7-25.

8. Eisenber, F.; Schulz, W. Biopolymers 1992, 32, 16431664.

9. Tang, H-R.; Brun, A.; Hills, B. Carbohydr Polym 2001, 46, 7-18.

10. Yakubu, P. I.; Ozu, E. M.; Baianu, I. C.; Orr, P. H. J Agric Food Chem 1993, 41, 162-167.

11. Hedley, C. L.; Bogracheva, T. Y.; Wang, T. L. Starch/ Stärke, in press; 
12. Cooke, D.; Gidley, M. J. Carbohydr Res 1992, 227 , 103-112.

13. Gidley, M.; Bociek, S. M. J Am Chem Soc 1985, 107, 7040-7044.

14. Bogracheva, T. Y.; Wang, Y. L.; Hedley, C. L. Biopolymers 2001, 58, 247-259.

15. Buleon, A.; Bizot, H.; Delage, M. M.; Pontoire, B. Carbohydr Polym 1987, 7, 461-482.

16. Nara, S.; Komia, T. Starch/Stärke 1983, 35, 407-410.

17. Bogracheva, T. Ya.; Morris, V. J.; Ring, S. G.; Hedley, C. L. Biopolymers 1998, 45, 323-332.

18. Donovan, J. W. Biopolymers 1979, 18, 263-275.

19. Wang, T. L.; Bogracheva, T. Ya.; Hedley, C. L. J Ex Bot 1998, 49, 481-502.

20. Galliard, T. Starch: Properties and Potential; John Wiley \& Sons: New York, 1987; Chap 2.

21. Bershtein, V. A.; Egorov, V. M. Differential Scanning Calorimetry of Polymers. Physics, Chemistry, Analysis, Technology; Ellis Horwood: New York, London, Toronto, Sydney, Tokyo, Singapore, 1994.

22. Bogracheva, T. Y.; Cairns, P.; Noel, T. R.; Hulleman, S.; Wang, T. L.; Morris, V. J.; Ring, S. G.; Hedley, C. L. Carbohydr Polym 1999, 39, 303-331.

23. Bogracheva, T. Ya.; Davydova, N. I.; Genin, Ya. V.; Hedley, C. L. J Ex Bot 1995, 46, 1905-1913.

24. Davydova, N. I.; Leont'ev, S. P.; Genin, Ya. V.; Sasov, A. Yu.; Bogracheva, T. Ya. Carbohydr Polym 1995, 27, 109-115.

25. Wang, Y-J.; White, P.; Pollak, L. Cereal Chem 1992, 69, 328-334.

26. Gernat, Ch.; Radosta, S.; Damaschun, G.; Schierbaum, F. Starch/Stärke 1990, 42, 175-178.
27. Hartley, L.; Chevance, F.; Hill, S. E.; Mitchel, J. R.; Blanshard, J. M. V. Carbohydr Polym 1995, 28, 83-89.

28. Morgan, K. R.; Furneaux, R.; Larsen, N. G. Carbohydr Res 1995, 276, 387-399.

29. Barsby, T L.; Donald, A. M.; Frazier, P. J. Starch Advances in Structure and Function; The Royal Society of Chemistry: Cambridge, 2001; Chap 9.

30. Visser, R. G. F.; Suurs, L. C. J. M.; Steeneken, P. A. M.; Jacobsen, E. Starch/Stärke 1997, 49, 443448.

31. Whittam, M. A.; Noel, T. R.; Ring, S, G. Int J Biol Macromol 1990, 12, 359-362.

32. Biliaderis, C. G.; Page, C. M.; Maurice, T. J.; Bienvenido, O. J. J Agric Food Chem 1986, 34, 6-14.

33. Stephen, A. M. Food Polysaccharides and Their Applications; Marcel Dekker: New York, 1995; Chap 2.

34. Elliasson, A-C.; Finstad, H.; Ljunger, G. Starch/Stärke 1988, 40, 95-100.

35. Kugimiya, M.; Donovan, J. W.; Wong, R. Y. Starch/ Stärke 1980, 32, 265-270.

36. Jovanovich, G.; Anon, M. C. Biopolymers, 1999, 8189.

37. Bogracheva, T. Y.; Leontiev, S. P.; Genin, Y. V. Carbohydr Polym 1994, 25, 227.

38. Testa, R. F.; Morrison, W. R. Cereal Chem 1990, 67, 551-557.

39. Flory, P. J. Principles of Polymer Chemistry; Cornell University Press: Ithaca, NY, 1953.

40. Timasheff, G. D.; Fasman, G. D. Structure and Stability of Biological Macromolecules; Marcel Dekker: New York, 1969. 